\title{
Characterization of surface sediments from the Beijing-Hangzhou Grand Canal (Zaozhuang section), China: assessment of beryllium enrichment, biological effect, and mobility
}

\author{
Wen Zhuang ${ }^{1,3}$ - Qing Chen ${ }^{2}$ Xuelu Gao ${ }^{3}$ Fengxia Zhou ${ }^{3}$ - Mantang Wang ${ }^{1}$. \\ Yongxia Liu ${ }^{1}$
}

Received: 14 October 2015 / Accepted: 4 May 2016 /Published online: 11 May 2016

(C) Springer-Verlag Berlin Heidelberg 2016

\begin{abstract}
The South-to-North Water Diversion Project is one of the world's largest water diversion projects, benefiting seven million people in China. The Zaozhuang section of the Beijing-Hangzhou Grand Canal is an important part of this project. This paper investigated the enrichment, biological effect, and mobility of beryllium (Be) in surface sediments of the Zaozhuang section. Results showed that high values were found in Tai'erzhuang District, Zaozhuang city, and the areas near the inlet of the Nansihu Lake, which might have been influenced by local human activities including metallurgy, burning of fossil fuels, and transportation. Four geochemical fractions of Be were obtained: acid-soluble fraction, reducible fraction, oxidizable fraction, and residual fraction. The nonresidual fractions (the sum of the first three) accounted for $72.5 \sim 96.1 \%$ of the total amount of Be. Acid-soluble fraction might be mainly influenced by human activities, with the strongest mobility and bio-availability, accounting for $4.1 \sim 44.7 \%$ of the total amount, with an average of $20.2 \%$. Enrichment factor (EF) showed minor to moderate enrichment in some regions; adverse effect index (AEI) also showed that there were high levels of $\mathrm{Be}$ in some regions, which might have negative impacts on organisms. Generally, mobility, EF,
\end{abstract}

Responsible editor: Philippe Garrigues

Wen Zhuang

wzhuang@yic.ac.cn

1 College of City and Architecture Engineering, Zaozhuang University, Zaozhuang, Shandong 277160, China

2 College of Life Sciences, Zaozhuang University, Zaozhuang, Shandong 277160, China

3 Key Laboratory of Coastal Environmental Processes and Ecological Remediation, Yantai Institute of Coastal Zone Research, Chinese Academy of Sciences, Yantai, Shandong 264003, China and AEI of elements are carried out separately. But the results of this study indicated that a comprehensive assessment on the enrichment, mobility, and biological effects of Be caused by human activities is necessary in understanding the environmental risks of Be.

Keywords Sediment · Enrichment factor · Adverse effect index $\cdot$ Fraction $\cdot$ The Beijing-Hangzhou Grand Canal

\section{Introduction}

Beryllium (Be) is a kind of highly toxic metal, which is transported in the water column, accumulated in sediments, and biomagnified through the food chain, resulting in remarkable risks to aquatic organisms and humans. Be can cause pulmonary granulomas and lung cancer, so it is a crucial cause of occupational diseases (Zhang et al. 2011; Hulo et al. 2016). Be has been determined as one of the 13 metal contaminants given priority to be controlled in the water environment by the US Environmental Protection Agency (USEPA 1979). In the natural environment, the elemental Be has very low toxicity, while the chemical and ionic fractions are extremely toxic. Be generated by human activities is mainly from the manufacturing of electronic products, metallurgy, automobile exhaust, and burning of fossil fuels (Edmunds, 2011). The level of $\mathrm{Be}$ in natural water bodies is very low. Be is mainly bound to the sediments, and the content of $\mathrm{Be}$ in the sediments is generally several orders of magnitude higher than that in the water bodies. Metallic elements, such as Be in the sediments, may be re-released into the water through a series of physical, chemical, and biological processes, which may cause secondary pollution of the water environment (Edmunds 2011; Zhuang and Gao 2014). 
The South-to-North Water Diversion Project is a strategic infrastructure of cross-regional deployment of water resources and one of the world's largest water diversion projects. The eastern route of the project is $1191 \mathrm{~km}$ in length, with official operations initiated in 2013, making a very important contribution to alleviate the severe water shortage in northern China. In particular, the Zaozhuang section of the Beijing-Hangzhou Grand Canal (hereinafter referred to as the Zaozhuang section) is an important part of the eastern route of the diversion project. The Zaozhuang section runs $42.5 \mathrm{~km}$ from the eastern inlet of the Nansihu Lake to the Middle Canal in Jiangsu Province. At present, in the Zaozhuang section, there are four integrated ports, the "golden waterway" and "National Civilized Model Channel" that perennially allows 1000-ton ship to ply. Large and small industrial enterprises such as chemical, metallurgical, plants, paper mills, machinery works, and cement plants are distributed along the banks of the Zaozhuang section. The National Highway 104, BeijingTaipei Expressway, and Beijing-Shanghai Railway pass through the Zaozhuang section in the west; the south bank of the Zaozhuang section is near Xuzhou City, whose mainstay industries include iron and steel, coal, and electricity. The development and utilization of coal is one of the primary sources of Be in natural environments, and metallurgical industry can also cause serious Be pollution (Sutton et al. 2012; Hulo et al. 2016). Therefore, human activities around the Zaozhuang section will undoubtedly bring huge threat to the ecosystem of the lake areas and can be the major source of $\mathrm{Be}$ in the environment, and the potential contamination problems of $\mathrm{Be}$ in the environment in the region cannot be ignored.

Over the years, there have been many studies on the environmental pollution of heavy metals, such as arsenic, mercury, cadmium, chromium, copper, nickel, lead, and zinc, while there were few studies on the geochemical characteristics and potential ecological risks of $\mathrm{Be}$ in environmental media, and reports on Be in sediments of lakes and rivers could be even more rare. Countries such as Canada and the Netherlands have set relevant standards on the Be levels in the soil (VROM 2000; CCME 2011). However, quality standards of China on soil or sediment did not include any related indicators of Be levels. This shows that the dangers of $\mathrm{Be}$ in sedimentary environment has not drawn sufficient attention from China's researchers and the relevant government departments.

Many researchers adopted the method of enrichment factor (EF) to determine the element enrichment caused by human activities (Alexander et al. 1993). The EF formula uses an internal reference value (normalization factor) to weaken the deviation between the different types of sediments, which is expressed as:

$\mathrm{EF}=\left[C_{x} / C_{i}\right]_{\text {Sample }} /\left[C_{x} / C_{i}\right]_{\text {Background }}$ where $C_{\mathrm{x}}$ and $C_{i}$ respectively represent the levels of the element $X$ and the normalized element in the samples and in the background values. Major elements such as $\mathrm{Al}$ and Fe share a similar distribution pattern, so $\mathrm{Fe}$ and $\mathrm{Al}$ are often used as a normalized element (Gao and Chen 2012). According to their enrichment factors, the sediments can be divided into seven classes: (1) $\mathrm{EF}<1$, no enrichment; (2) $1<\mathrm{EF}<3$, slight enrichment; (3) $3<\mathrm{EF}<5$, moderate enrichment; (4) $5<\mathrm{EF}<10$, moderately severe enrichment; (5) $10<\mathrm{EF}<25$, severe enrichment; (6) $25<\mathrm{EF}<50$, highly severe enrichment; and (7) EF $>50$, extremely severe enrichment (Zhuang and Gao 2014).

However, merely calculating the enrichment factors cannot be directly used to assess the extent of the adverse effects of the elements on the benthos (Hamdoun et al. 2015). Many quality standards on sediments are used to assess the quality conditions of the sedimentary environment. Among them, the threshold effects level (TEL) has been proved to be an effective sediment quality standard (Long et al. 2000; Sundaray et al. 2011). Muñoz-Barbosa et al. (2012) suggested comparing the measured level of the element with its corresponding TEL value to assess the adverse effect index (AEI), which is expressed as:

$\mathrm{AEI}=[X] /[\mathrm{TEL}]$

where $[X]$ refers to the levels of the element in the samples and TEL refers to the threshold effect level. If $\mathrm{AEI} \leq 1$, then element level in the sample is too low to produce adverse effects on the benthos; if AEI > 1, then element level in the sample can be high enough to produce adverse impacts on the benthos (Muñoz-Barbosa et al. 2012).

Besides the enrichment factor and sediment quality standard mentioned above, the fractional characteristics of metallic elements in sediments are also important in environmental risk assessment. The toxicity and bio-availability of metallic elements in sediments are closely related to the geochemical characteristics of the sediments, such as the contents of iron/manganese oxides and organic carbon, the types of clay minerals, etc. These geochemical characteristics influence toxicity and bio-availability of metallic elements by changing their fractional characteristics in sediments. Whether a metallic element in sediment can exchange with the overlying water depends on its existing forms in sediment. Different forms of metallic elements show different geochemical behaviors and bio-availability (Gao et al. 2010; Zhang et al. 2013). Only the forms with high mobility that have been re-released into the water through the complex, reduction and dissolution can become a crucial factor affecting the nutrition and pollution of waters (Tessier et al. 1979). Therefore, fractional research on metallic elements is more effective on revealing the actual environmental risk of them than simple content determination. Sources of metallic elements in sediments are much 
different from each other, but the geochemical characteristics of metallic elements are universal, which make the sequential extraction procedures to be important methods to investigate the metal forms in sediments (Tessier et al. 1979). Some of those widely adopted are the five-step continuous extraction method proposed by Tessier et al. (1979) and the four-step continuous extraction method recommended by the former European Community Bureau of Reference (BCR) (Rauret et al. 1999). The determination of forms of metallic elements in sediments is of great importance for revealing their origins and migration patterns and exploring the environmental pollution level and bio-availability.

In conclusion, the purposes of this study was to assess the enrichment, biological effect, and mobility of Be in surface sediment of the Beijing-Hangzhou Grand Canal (Zaozhuang Section), providing important reference data for the development and implementation of measures related to environmental protection and pollution control in the South-to-North Water Diversion Project.

\section{Materials and methods}

\section{Sample collection}

In April 2015, a stainless steel grab bottom sampler was used to collect 14 samples of surface sediments of the Zaozhuang section $(0 \sim 5 \mathrm{~cm}$, Fig. 1). After mixing, the samples were put in polyethylene bags and quickly placed into the cooler box with ice packs. The polyethylene bags were soaked in $10 \%$ $\mathrm{HNO}_{3}(v / v)$ for more than $48 \mathrm{~h}$ before sampling and were rinsed with Milli-Q water. The samples were shipped back to the laboratory to be stored at $4{ }^{\circ} \mathrm{C}$. During the sampling which coincided with the diversion period of the South-toNorth Water Diversion Project, the water flowed from west to east.

\section{Sample analysis}

The samples were naturally dried in cool air, before they were ground and sieved through a 200-mesh sieve. A high-pressure wet acid digestion $\left(\mathrm{HF}, \mathrm{HNO}_{3}\right.$, and $\mathrm{HClO}_{4}$ mixed at a volume ratio of 5:2:1) was employed to obtain the overall information of Be in surface sediments (Gao et al. 2010). The geochemical morphological information of $\mathrm{Be}$ was obtained with the $\mathrm{BCR}$ sequential extraction procedure (Rauret et al. 1999); this method divided the geochemical forms of heavy metals into four categories: acid-soluble fraction, reducible fraction, oxidizable fraction, and residual fraction, hereinafter abbreviated as F1, F2, F3, and F4. The first three fractions are called extractable fraction. The levels of Be were determined by an inductively coupled plasma mass spectrometer (PerkinElmer, Elan DRC II); the levels of $\mathrm{Al}$ and Fe were determined by an inductively coupled plasma optical emission spectrometry (PerkinElmer, Optima 7000DV).

Proper amount of wet samples were mixed but not ground, and particles larger than $2 \mathrm{~mm}$ were removed. The particle size was measured by a laser particle size analyzer (Malvern, Mastersizer 2000) with a measurement range of $0.02 \sim 2000 \mu \mathrm{m}$. According to the particle diameter, the sediments were divided into three classes: $<4 \mu \mathrm{m}$, clay; $4 \sim 63 \mu \mathrm{m}$, silt; $>63 \mu \mathrm{m}$, sand. The level of total organic carbon (TOC) of the sediment samples, which had been dried and carbonateremoved with $\mathrm{HCI}$, was determined by an elemental analyzer

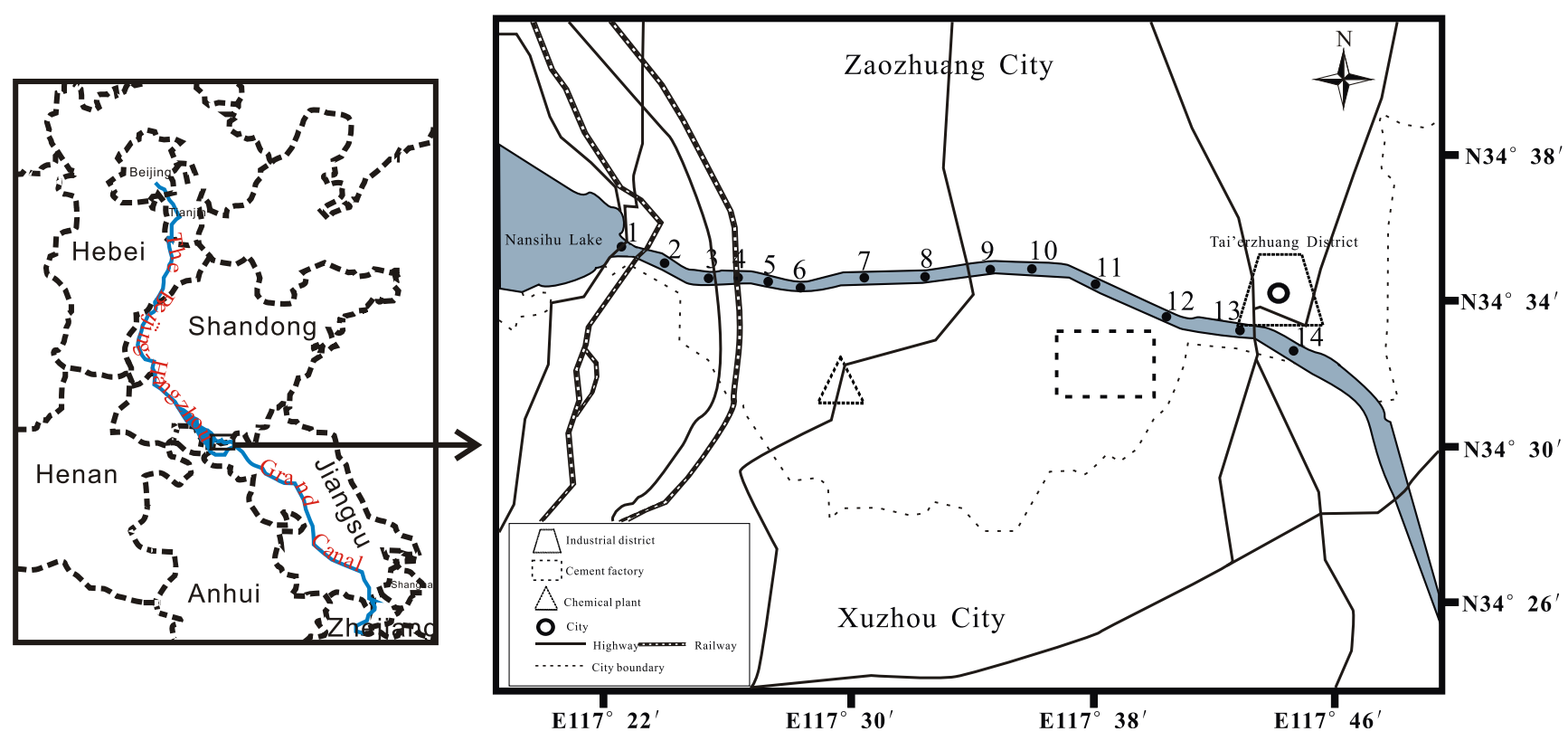

Fig. 1 Location of the sampling sites in the Beijing-Hangzhou Grand Canal (Zaozhuang section) 
(Elementar, vario MACRO cube). See specific analysis of particle size and organic carbon in the literature (Zhuang and Gao 2013).

\section{Quality assurance and quality control}

Reliability of data was guaranteed by the use of laboratory quality assurance and quality control methods, including standardized test procedures, analysis of reagent blanks, calibration of standard solution, recovery of reference material, and analysis of parallel sample. All reagents were of guaranteed or higher purity, and all plastic containers were soaked in $10 \%$ nitric acid $(v / v)$ for more than $48 \mathrm{~h}$ before use and were rinsed with Milli-Q water and dried.

Recovery of total contents of $\mathrm{Be}, \mathrm{Al}$, and $\mathrm{Fe}$ in sediment samples was estimated through the recovery of reference materials, including sediment reference materials GBW-07333 and GBW07309. The difference between the measured values and the appraised values of the reference materials was within $10 \%$. Recovery of speciation of Be was estimated indirectly through the recovery of reference material GBW07436. Since there is no information about speciation of $\mathrm{Be}$ on the product specification of GBW07436, recoveries of speciation of $\mathrm{Cr}$, $\mathrm{Cu}, \mathrm{Ni}$, and $\mathrm{Zn}$ were used as reference values for $\mathrm{QA}$ and $\mathrm{QC}$. The differences between the measured values and the appraised values of acid-soluble fraction, reducible fraction, oxidizable fraction, and residual fraction for the four metallic elements hereinbefore were within $30,20,20$, and $10 \%$, respectively. Parallel double-sample method was used in all experiments.

\section{Results and discussion}

\section{Total contents and fraction characteristics}

\section{Total contents characteristics of Be}

The total content of Be in surface sediments from each sampling point of the Zaozhuang section was shown in Fig. 2. The total contents of $\mathrm{Be}$ in sediments ranged from 0.73 to $1.58 \mu \mathrm{g} \mathrm{g}^{-1}$, with an average of $1.00 \mu \mathrm{g} \mathrm{g}^{-1}$. The peak value of the total content of Be was found at site 14, which might be affected by the surrounding metallurgy, machinery manufacturing, and other industries near Tai'erzhuang. The second highest value was found at site $7\left(1.28 \mu \mathrm{g} \mathrm{g}^{-1}\right)$ and the third at site $1\left(1.26 \mu \mathrm{g} \mathrm{g}^{-1}\right)$. Site 7 was close to villages, and there was a drainage ditch near it. Site 1 was located near a small thermal power plant, and just its upstream there are the 104 national road, Jingtai highway, and the Beijing-Shanghai high-speed railway. Therefore, the coal combustion and exhaust emissions might be the causes of relatively high levels of $\mathrm{Be}$ in this site. Be contents in sediments at site $8 \sim 12$ were all relatively low. There are only farmland on both sides of these sites, with no obvious pollution sources of Be.

Quantitative results of particle size and TOC contents were shown in Fig. 3. The mineral fraction of particles less than $4 \mu \mathrm{m}$ (clay) varied from nearly 0.3 to $36.3 \%$ with an average of $21.3 \%$. The fraction of 4-63- $\mu \mathrm{m}$ (silt) particles varied from 37.1 to $75.6 \%$ with an average of $65.2 \%$. Sand content $(>63 \mu \mathrm{m})$ varied from 2.7 to $62.7 \%$ with an average of $13.5 \%$. Therefore, the surface sediments in the Zaozhuang section were mainly composed of fine components (clay+ silt). The TOC contents in sediments varied from 0.14 to $0.75 \%$ with an average of $0.35 \%$.

Many studies have shown that TOC contents and finegrained component in sediments are significantly positively correlated with the contents of metallic elements, because they can easily capture the metal ions in water by adsorption or complexation (Duan et al. 2010). However, in this study, the TOC contents, clay and silt were not significantly correlated with Be contents $(r<0.4, p>0.05)$. Liu et al. (2008) believed that the metabolism of anaerobic microorganisms was vigorous in deep sediments $(>20 \mathrm{~cm})$, accumulating a lot of organic matters; therefore, the level of metallic elements was obviously influenced by TOC in deep sediments. Moreover, since the levels of TOC were low in surface sediments, its influence on metallic elements was not obvious (Liu et al. 2008). Liu et al. (2007) found that the TOC contents varied from 1 to $23.5 \%$ in the sediment of the Nansihu Lake and its main inflow rivers
Fig. 2 The spatial variations of the total contents and different geochemical fractions of $\mathrm{Be}$ in surface sediments of the BeijingHangzhou Grand Canal

(Zaozhuang section)

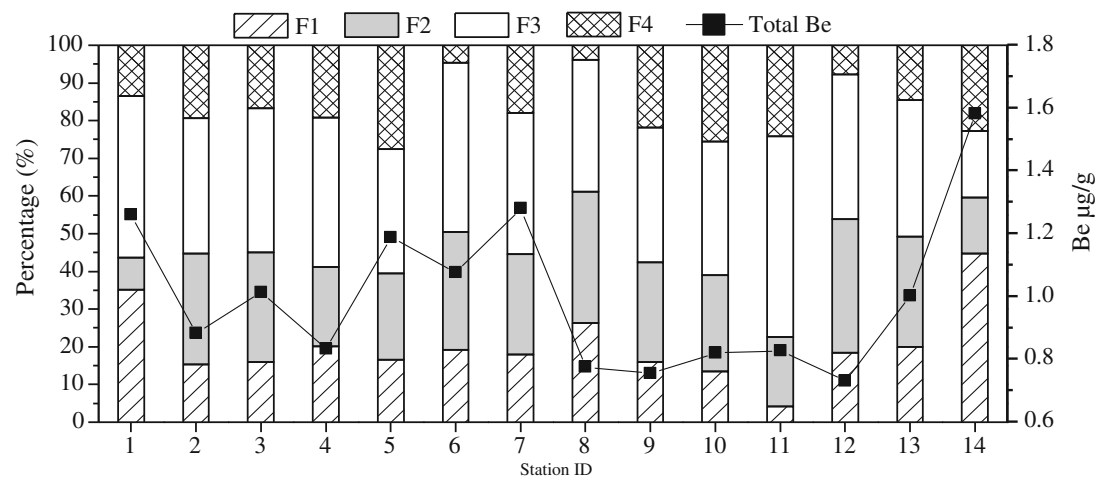


Fig. 3 The spatial distributions of grain size and TOC contents in the surface sediments

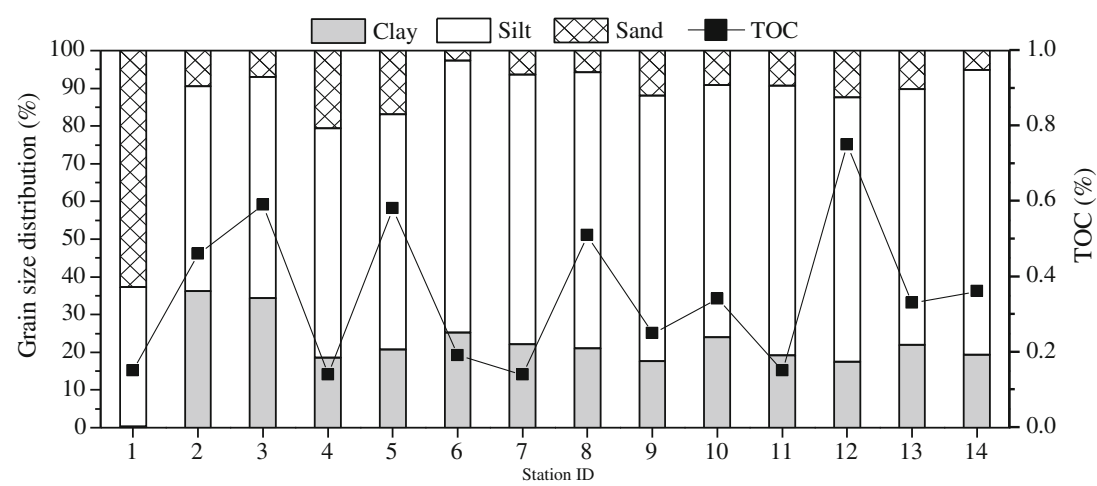

(not including the Zaozhuang section of the BeijingHangzhou Grand Canal), which were much higher than the contents in the present study. The contents of TOC were significantly positively correlated with the contents of metals in their study. So the low TOC contents might be one of the reasons that TOC contents had no significant correlation to Be contents in the present study.

A previous study showed that metallic elements have no significant correlation with TOC and particle size in surface sediments from the Yellow River Estuary (Wu et al. 2013). The authors attributed this to the complicate hydrological conditions in the Yellow River Estuary, including the complex sources of metallic elements, the variation of water, and sediment contents and the impact of human activities. The surrounding areas of the Zaozhuang section have been strongly influenced by domestic sewage, industrial wastewater, and farmland irrigation, coupled with the fact that the Zaozhuang section is an important waterway, with frequent dredging and intense disturbance of sediments. Therefore, the controlling effects of TOC and particle size were not obvious.

Currently, there is a lack of geochemical background data of elements in sediments of the Zaozhuang section. The Beijing-Hangzhou Grand Canal (Zaozhuang section) directly connects to the Nansihu Lake which lies in the transition zone between Shandong Hills and Yellow River alluvial plain. The Nansihu Lake was originally the area flew through by ancient Sishui River. In the twelfth century, flood broke out in the south region of the Yellow River and occupied watercourse of ancient Sishui River, and resulted in the blockage of drainage, then silting-up into the lake. The surrounding area of the Nansihu Lake is irrigated by the Yellow River water; meanwhile, huge amounts of sediment is brought into the lake since. Before the formal operation of the East Line of the South-to-North Water Diversion Project, the direction of flow in the study area is from the Nansihu Lake to the Zaozhuang section. According to literature, Be content in sediment of the Yellow River was taken as representative of the background level of Be is reasonable (Guo Yongsheng 1990; Dong 2009; Baidu Encyclopedia, http://baike.baidu.com/link?url=
16V9jLgakSo1eVhGyqZKAEPeJ4f9F-pEypXx3vS9StAg 1b9X4_NPCLv7Ps2vbs75PmS5nXjZLajvLyOvJKvQw_).

This study used the element levels in sediments of Yellow River as the background value, and the background level of $\mathrm{Be}$ is $1.7 \mu \mathrm{g} \mathrm{g}^{-1}$ (Zhao Yiyang and Yan Mingcai 1992). Be levels in sediments at all positions were lower than the background value.

As the current related environmental standards of China lack the provision on Be levels in sediments, the target value $\left(1.1 \mu \mathrm{g} \mathrm{g}^{-1}\right)$ and intervention value $\left(30 \mu \mathrm{g} \mathrm{g}^{-1}\right)$ of Be in the Dutch soil standards were referenced in this paper (VROM 2000). The target value indicates the level at which there is a sustainable soil quality. In terms of curative policy, this means that the target value indicates the level that has to be achieved to fully recover the functional properties of the soil for humans and plant and animal life. Besides this, the target value gives an indication of the benchmark for environmental quality in the long term on the assumption of negligible risks to the ecosystem. Intervention value indicates that the functional characteristics needed for the survival of human, plants, and animals of the soil with higher levels have been severely damaged or threatened, and a mandatory intervention must be implemented. The target value and intervention value are based on extensive studies of both human and ecotoxicological effects of soil/sediment contaminants. For soil/sediment, the target value has been checked for the practical feasibility in a project evaluating the use of target value, which was carried out in the period 1996-1998 (VROM 2000).

Be levels at sites 1, 5, 7, and 14 were slightly higher than the target value, while the levels at all the positions were far lower than the intervention value. Generally, Be levels in surface sediments of the Zaozhuang section were relatively low.

\section{Fraction characteristics and mobility of $\mathrm{Be}$}

The distribution of Be fractions in surface sediments from each sampling site of the Zaozhuang section was shown in Fig. 2. F1, including the exchangeable and carbonate-bound fractions, was mainly from human activities, with strong mobility and bio-availability, as well as the highest environmental 
hazard (Karbassi and Shanka 2005). F1 in the surface sediments of the Zaozhuang section accounted for $4.1 \sim 44.7 \%$ of the total contents of Be, with an average of $20.2 \%$. Its peak value was found at site 14 , and the second highest value $(35.1 \%)$ was found at site 1 , consistent with the total content of $\mathrm{Be}$, showing the contributions to Be levels made by metallurgy, automobile exhaust, and human activities.

$\mathrm{F} 2$, which represented the fractions bound to $\mathrm{Fe} / \mathrm{Mn}$ oxides or hydrated oxides, could be re-released from sediments into water under reducing conditions and thus obtained bio-availability. F2 levels ranged from 8.7 to $35.5 \%$, averaged $25.3 \%$. F3 referred to the fractions bound to organic substances, which could be mineralized and decomposed into inorganic substances in an oxidizing environment, and the fractions bound to them could be re-released into the water (Karbassi and Shankar 2005). F3 levels ranged from 17.6 to $53.1 \%$, averaged $37.4 \%$. Usually, environmental factors such as $\mathrm{pH}$, alkalinity, oxidation-reduction quality, and grain size have great influence on the distribution of different forms of metallic elements, so F1, F2, and F3 could transform into each other to a certain extent (Xu et al. 2012). The sum of the first three fractions accounted for as high as $72.5 \sim 96.1 \%$ of the total contents of Be, averaged $82.9 \%$, with strong mobility.

$\mathrm{F} 4$, which represented the inert components of Be in sediments, mainly mineral phases bound to the crystal lattice of sediments, was a natural source of Be and could hardly be utilized by organisms. F4 levels ranged from 3.9 to $27.5 \%$, with an average of $17.1 \%$.

\section{Evaluation of enrichment and biological effect}

\section{Evaluation of enrichment factor}

In this study, $\mathrm{Al}$ was used as the reference element for geochemical normalization, because $\mathrm{Al}$ represents the quantity of aluminosilicates which is generally the predominant carrier phase for metals in sediments and its natural concentration tends to be uniform (Gao et al. 2015). The background levels of $\mathrm{Be}$ and $\mathrm{Al}$ were 1.7 and $65.2 \mathrm{mg} \mathrm{g}^{-1}$, respectively (Zhao and Yan 1992; Meng et al. 2010). Results of enrichment factor analysis were shown in Fig. 4. The top three EF values were recorded in sites 1,2 , and $3(3<\mathrm{EF} \leq 5)$, indicating moderate

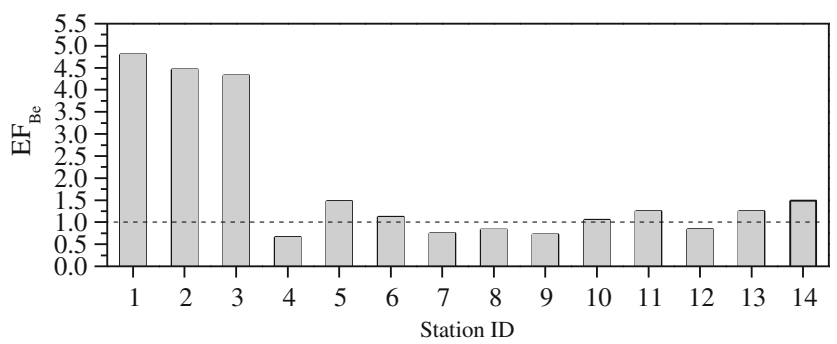

Fig. 4 The spatial distributions of EF values for Be in the surface sediments enrichment of Be at these sites. These sites were surrounded by a thermal power plant, the 104 national road, Jingtai highway, and the Beijing-Shanghai high-speed railway, so they might suffer fierce impact of human activities. EF values for sites $5,6,10,11,13$, and 14 were between 1 and 3 , indicating minor enrichment. EF values for the remaining five sites were less than 1, showing no significant enrichment. On the whole, the degree of enrichment was at minor to moderate level.

\section{Evaluation of biological effect}

Since there is no corresponding TEL value of $\mathrm{Be}$, the target value $\left(1.1 \mu \mathrm{g} \mathrm{g}^{-1}\right)$ of the Dutch "Soil Protection Act" was adopted in this study to replace it (VROM, 2000). Results of AEI analysis were shown in Fig. 5. AEI showed that Be levels were high in sediments of some areas, which might have adverse effects on the benthos. Enrichment factor also suggested that there was significant enrichment of Be in surface sediments of some sampling sites.

In fact, in terms of selection of background values, the background value of $\mathrm{Be}$ in the investigated area was $1.7 \mu \mathrm{g} \mathrm{g}^{-1}$, higher than the specified target value of $1.1 \mu \mathrm{g} \mathrm{g}^{-1}$ by the Dutch Soil Protection Act. Be levels in sediments at all positions were lower than the background value; however, in view of the target value was exceeded, it should be a necessity for further investigation. While there was a current lack of related standards on Be levels in soil and sediments in China, causing some difficulties in evaluation of ecological risks, we suggest that toxicity tests, bioaccumulation tests, and other related experiments should be further carried out in order to make the risk assessment methods more accurate and reliable in the analysis of sedimentary Be.

\section{Correlation between EF and AEI}

Results of correlation analysis of EF and AEI were shown in Fig. 6. Linear regression analysis showed there was no significant association between EF and AEI $(r=0.22, p>0.05)$. AEI was calculated only based on the concentrations of $\mathrm{Be}$, whereas a normalization factor was employed in EF calculation. AEI reflected the degree that content of Be exceeded a threshold value, while EF reflected the contribution of human

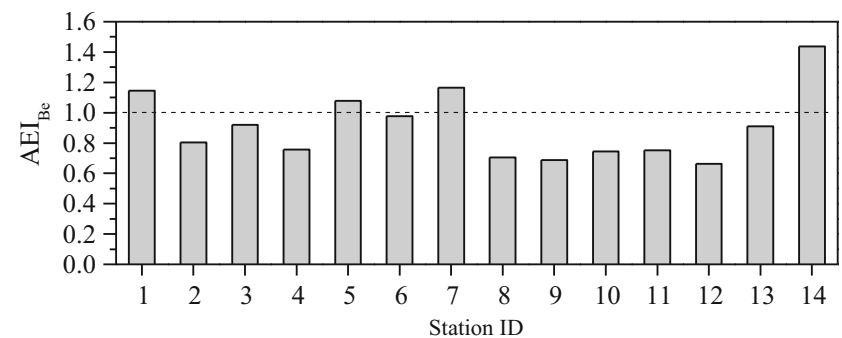

Fig. 5 The spatial distributions of AEI values for Be in the surface sediments 


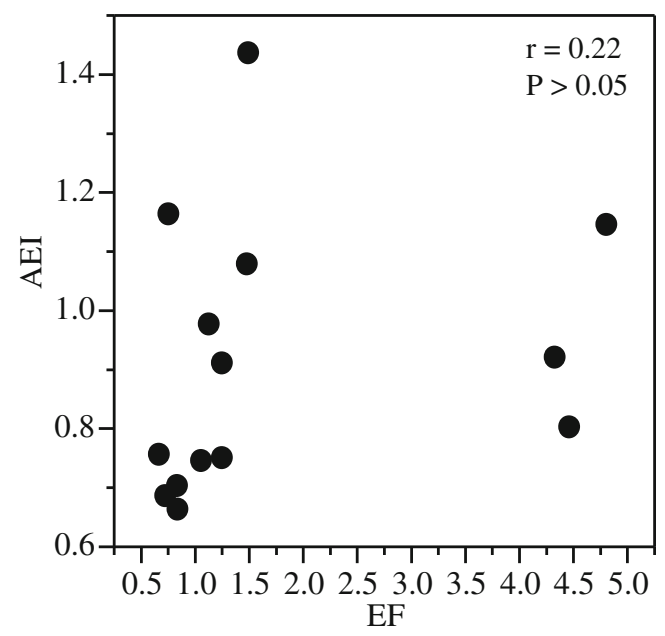

Fig. 6 Relationships between EF and AEI for Be

activities towards content of Be. In other words, the mechanisms of EF and AEI are divergent and they are used to assess the environmental risk from different angles. Actually, the enrichment and loss of elements in the natural condition, such as the biological cycle, could also affect the distribution of the elements (Reimann and Caritat 2000, 2005). Thus, the different choices of normalization factors might also lead to different results. Therefore, only using one risk assessment method could not actually reflect the environmental quality condition of the specific region, and a variety of methods from many different aspects should be used in environmental risk assessment.

\section{Correlation between EF, AEI, and Be fractions}

Results of correlation analysis of EF, AEI, and Be fractions were shown in Fig. 7. The EF was insignificantly correlated with Be of F1 or the extractable fractions $(\mathrm{F} 1+\mathrm{F} 2+\mathrm{F} 3)$ $(r<0.5, p>0.05)$; the cause might be that a normalization factor was employed in EF calculation. Studies have shown that the enrichment of metallic elements in sediments caused by human activities showed a strong mobility (Baize et al. 2009; Leleyter et al. 2012). AEI was significantly correlated with F1 and extractable fractions $(r=0.83$ and 0.93 , respectively, $p<0.001$ ), indicating that non-residual fractions of $\mathrm{Be}$ significantly contributed to AEI and human activities were the important factors producing adverse effects of Be in sediments on the benthos.

\section{Conclusion}

In this paper, the levels, enrichment, mobility, and possible adverse effects on organisms of Be in surface sediments of the Beijing-Hangzhou Grand Canal (Zaozhuang section) were investigated. In particular, Be levels were relatively higher in
Fig. 7 The respective correlations of EF and AEI with Be fractions
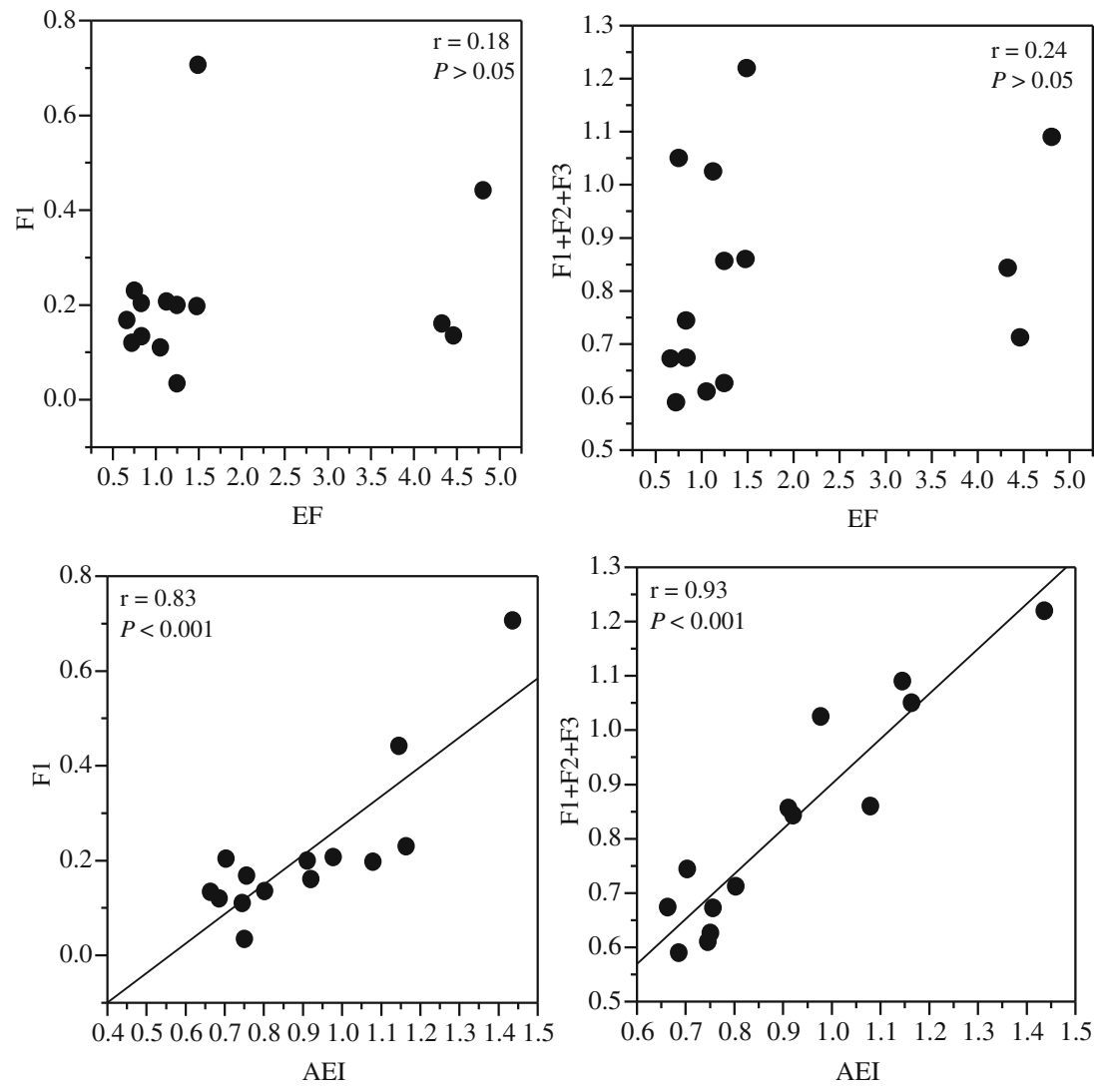
Tai'erzhuang District, Zaozhuang, and the areas near the inlet of the Nansihu Lake, which might have been influenced by human activities, including local industrial sewage, burning of fossil fuels, and transportation. But the overall level of Be in sediments was generally low, and level of Be in neither site was higher than the background value. However, EF analysis showed obvious enrichment of $\mathrm{Be}$ and the enrichment degree was at minor to moderate level. Results of AEI analysis also suggested that Be levels were high in sediments of some areas, which might generate adverse effects on organisms. Fraction analysis indicated that non-residual fraction of $\mathrm{Be}$ in sediments accounted for a high proportion of the overall level, with a strong mobility.

Correlation analysis showed that Be mobility was significantly correlated with AEI but not with EF. But indeed the enrichment of $\mathrm{Be}$ in sediments is one of the factors increasing environmental risks. There was no significant association between AEI and EF either. The mechanisms of EF and AEI are divergent and they are used to assess the environmental risk from different angles. Nevertheless, if the mobility and enrichment of Be are taken into comprehensive consideration, it will be more conducive to an overall and detailed understanding of the relationship between the impacts of human activities and the migration of $\mathrm{Be}$.

Acknowledgements This study was co-supported by the Natural Science Foundation of Shandong Province, China (ZR2014DP005, ZR2013CL027), and the Research Fund for the Doctoral Program of Zaozhuang University, China (2014BS11, 2014BS14).

\section{References}

Alexander CR, Smith RG, Calder FD, Schropp SJ, Windom HL (1993) The historical record of metal enrichments in two Florida estuaries. Estuaries 16:627-637

Baize S, Lemeille F, Cushing M, Schwenninger JL, Nicoud G (2009) Multidisciplinary approach to study the Vuache fault (France) - part I: geological characterization of the fault, International Conference Provence, Aix-en-Provence

CCME (Canadian Council of Ministers of the Environment) 2011. Canadian Environmental Quality Guidelines. Http://www.ccme.ca/ en/resources/canadian_environmental_quality_guidelines/index. html.

Dong XJ (2009) Annals of Weishan County 1991-2005. Shandong Pictorial Publishing House, Jinan, pp 54-60

Duan LQ, Song JM, Xu YY, Li XG, Zhang Y (2010) The distribution, enrichment and source of potential harmful elements in surface sediments of Bohai Bay, North China. J Hazard Mater 183:155-164

Edmunds WM (2011) Beryllium: environmental geochemistry and health effects. Encyclopedia of Environmental Health 293

Gao XL, Chen CTA (2012) Heavy metal pollution status in surface sediments of the coastal Bohai Bay. Water Res 46:1901-1911

Gao XL, Chen CTA, Wang G, Xue QZ, Tang C, Chen SY (2010) Environmental status of Daya Bay surface sediments inferred from a sequential extraction technique. Estuar Coast Shelf Sci 86: 369-378
Gao XL, Zhuang W, Chen CTA, Zhang Y, 2015. Sediment quality of the SW coastal Laizhou Bay, Bohai Sea, China: a comprehensive assessment based on the analysis of heavy metals. PLOS ONE, DOI: 10.1371/journal.pone.0122190.

Guo YS (1990) On historical change of lakes in Shandong Province. Transactions of Oceanology and Limnology 3(1):15-22 (In Chinese with English abstract)

Hamdoun H, Van-Veen E, Basset B, Lemoine M, Coggan J, Leleyter L, Baraud F (2015) Characterization of harbor sediments from the English Channel: assessment of heavy metal enrichment, biological effect and mobility. Mar Pollut Bull 90:273-280

Hulo S, Radauceanu A, Chérot-Kornobis N, Howsam M, Vacchin V, De Broucker V, Rousset D, Grzebyk M, Dziurla M, Sobaszek A, Edme JL (2016) Beryllium in exhaled breath condensate as a biomarker of occupational exposure in a primary aluminum production plant. Int $\mathrm{J}$ Hyg Environ Health 219:40-47

Karbassi AR, Shankar R (2005) Geochemistry of two sediment cores from the west coast of India. International Journal of Environmental Science and Technology 1:307-316

Leleyter L, Rousseau C, Biree L, Baraud F (2012) Comparison of EDTA, $\mathrm{HCl}$ and sequential extraction procedures, for selected metals $(\mathrm{Cu}$, $\mathrm{Mn}, \mathrm{Pb}, \mathrm{Zn}$ ), in soils, riverine and marine sediments. J Geochem Explor 116-117:51-59

Liu EF, Shen J, Yang LY, Zhu YX, Sun QY, Wang JJ (2007) Chemical fractionation and pollution characteristics of heavy metals in the sediment of Nansihu Lake and its main inflow rivers, China. Environmental Science 28:1377-1382 (In Chinese with English abstract)

Liu J, Zhang P, Chen YH, Qi JY, Wang J, Wang CL, Wang XY (2008) Determination of thallium chemical form in sediment core from Pear River. Journal of Guangzhou University 7(1):67-70 (In Chinese with English abstract)

Long ER, MacDonald DD, Severn CG, Hong CB (2000) Classifying probabilities of acute toxicity in marine sediments with empirically derived sediment quality guideline. Environ Toxicol Chem 19: 2598-2601

Meng XH, Liu EF, Yang LJ, Sun J, Yuan HZ (2010) Spatial distribution and contamination evaluation of metals in sediments from Nansihu Lake and its main inflow rivers. Research of Environmental Sciences 23:1-6 (In Chinese with English abstract)

Muñoz-Barbosa A, Gutiérrez-Galindo EA, Daesslé LW, Orozco-Borbón MV, Segovia-Zavala JA (2012) Relationship between metal enrichments and a biological adverse effects index in sediments from Todos Santos Bay, northwest coast of Baja California, México. Mar Pollut Bull 64:405-409

Rauret G, López-Sánche JF, Sahuquillo A, Rubio R, Davidson C, Ure A, Quevauviller P (1999) Improvement of the BCR three step sequential extraction procedure prior to the certification of new sediment and soil reference materials. J Environ Monit 1:57-61

Reimann C, Caritat DP (2000) Intrinsic flaws of element enrichment factors (EFs) in environmental geochemistry. Environ Sci Technol 34:5084-5091

Reimann C, Caritat DP (2005) Distinguishing between natural and anthropogenic sources for elements in the environment: regional geochemical surveys versus enrichment factors. Sci Total Environ 337:91-107

Sundaray SK, Nayak BB, Lin S, Bhatta D (2011) Geochemical speciation and risk assessment of heavy metals in the river estuarine sediments - a case study: Mahanadi basin, India. J Hazard Mater 186: 1837-1846

Sutton M, Bibby RK, Eppich GR, Lee S, Lindvall RE, Wilson K, Esser BK (2012) Evaluation of historical beryllium abundance in soils, airborne particulates and facilities at Lawrence Livermore National Laboratory. Sci Total Environ 437:373-383

Tessier A, Campbell PGC, Bisson M (1979) Sequential extraction procedure for the speciation of particulate trace metals. Anal Chem 51: 844-851 
USEPA (1979) Water related fate of the 129 priority pollutants. USEPA, Washington, D C, USA

VROM (2000) Intervention values and target values: soil quality standards. Ministry of Housing, Spatial Planning and Environment, Department of Soil Protection, The Hague, Netherlands

Wu B, Song JM, Li XG (2013) Environmental characteristics of heavy metals in surface sediments from the Huanghe Estuary. Environmental Science 34:1324-1332 (In Chinese with English abstract)

Xu YY, Song JM, Li XG, Yuan HM, Li N (2012) Variation characteristics and potential ecological risk assessment of heavy metals in the surface sediments of Bohai Bay. Environmental Science 33(3):732740 (In Chinese with English abstract)

Zhang YX, Sun JC, Huang GX, Liu JT, Jing JH, Xiang XP, Chen X, Wang JC, Cui HW (2011) Distribution of beryllium in shallow groundwater of the Zhujiang Delta and a preliminary analysis of its origin. Geol China 38(1):197-203 (In Chinese with English abstract)
Zhang R, Zhou L, Zhang F, Ding YJ, Gao JR, ChenJ YHQ, Shao W (2013) Heavy metal pollution and assessment in the tidal flat sediments of Haizhou Bay, China. Mar Pollut Bull 74:403-412

Zhao YY, Yan MC (1992) Comparison of chemical element abundances in sediments of the Yellow River, the Changjiang River and the shallow seas of China. Chin Sci Bull 13:1202-1204 (In Chinese)

Zhuang W, Gao XL (2013) Acid-volatile sulfide and simultaneously extracted metals in surface sediments of the southwestern coastal Laizhou Bay, Bohai Sea: concentrations, spatial distributions and the indication of heavy metal pollution status. Mar Pollut Bull 76: $128-138$

Zhuang W, Gao XL (2014) Integrated assessment of heavy metal pollution in the surface sediments of the Laizhou Bay and the coastal waters of the Zhangzi Island, China: comparison among typical marine sediment quality indices. PLoS One 9(4), e94145 